\title{
Lyophilisate and Solvent for Oral Suspension Dosage Form
}

National Cancer Institute

\section{Source}

National Cancer Institute. Lyophilisate and Solvent for Oral Suspension Dosage Form.

NCl Thesaurus. Code C149633.

Lyophilisate and solvent intended for the preparation of an oral suspension, for veterinary use, by dispersing the lyophilisate in the solvent. 